\title{
SCIDOC
}

\author{
International Journal of Dentistry and Oral Science (IJDOS) \\ ISSN: 2377-8075
}

\section{An in Vitro Comparative Evaluation of Microleakage of Conventional Gic \& New Modified Glass Ionomer Cement Nanozirconia Silica Hydroxyapatite Restorative Material}

\author{
Research Article
}

Dr. Vikas Bulkar ${ }^{1 *}$, Dr. Abhigyan Manas², Dr. Munaz Mulla³, Dr. Mushir Mulla ${ }^{4}$

${ }^{1}$ Senior Lecturer, Department of Prosthodontics, Al Badar Dental College and Hospital, Kalburgi-585102, Karnataka, India.

${ }^{2}$ Assistant Professor, Department of Oral and Maxillofacial Surgery, Career Post Graduate Institute of Dental Sciences and Hospital Lucknow, UP, India.

${ }^{3}$ Assistant Professor, Department of Periodontyology and Oral Medicine College of Dentistry, Qassim University, Saudi Arabia.

${ }^{4}$ Assistant Professor, Department of Dental Hygiene College of Applied Health Sciences in Arrass, Qassim University, Saudi Arabia.

\section{Abstract}

Introduction: The use of GIC as a luting agent, restorative material and base resulted in its popularity among dentists. Aim: The present study was conducted to compare the microleakage of conventional GIC with modified GIC-nanoZrO2-SiO2-HA hybrid material.

Materials \& Methods: The present in vitro study was conducted on 80 freshly extracted maxillary first or second premolars. Teeth were divided into two groups of 40 each. In group I, conventional GIC restorative material was used and in group II, GIC-nanoZrO2-SiO2-HA hybrid material was used. By dye penetration test microleakage was assessed at labial and lingual surfaces of teeth with stereomicroscope.

Results: The mean microleakage in group I was $0.64 \pm 0.13$ and in group II was $0.89 \pm 0.12$. The mean difference in both groups found to be -0.43 . Independent t- test showed significant difference between both groups $(\mathrm{P}<0.01)$.

Conclusion: The modified GIC-nanoZrO2-SiO2-HA hybrid material exhibited higher microleakage as compared to conventional GIC

Keywords: Dye Penetration; Glass Ionomer Cement; Microleakage.

\section{Introduction}

Glass ionomer cement (GIC) has been widely used since decades. With the progression of time there have been multiple modifications in its structure and composition which has increased its utility in endodontics. The use of GIC as a luting agent, restorative material and base resulted in its popularity among dentists [1].

The greatest advantage of GIC is the tooth colored restoration which is demanded by patients. They are concerned about their esthetics and hence are the material of choice. It is not only useful in permanent but also in primary teeth [2]. The presence of fluoride in GIC is beneficial in many terms. It helps in preventing progression of dental caries by releasing fluoride ions and by forming fluorapatite crystals which are more resistance to attack by bacteria. Thus in deciduous teeth which are more vulnerable to get dental caries, there use has been proved as boon. It is relatively easy to use and possess excellent bonding to both dentin and enamel. However, despite innumerate advantages, opacification, poor wear resistance and microleakage are among few disadvantages. The biggest failure of any restoration is its ability to prevent microleakage [3].

All these led to discovery of different modified advanced variety of GIC. In this category, modified GIC-nanoZrO2-SiO2-HA hybrid material is new one [4]. Considering this, the present study was conducted to compare the microleakage of conventional GIC with modified GIC-nanoZrO2-SiO2-HA hybrid material.

\section{Materials and Methods}

The present in vitro study was conducted in the department of

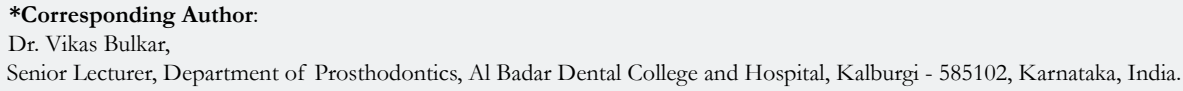

Citation: Dr. Vikas Bulkar, Dr. Abhigyan Manas, Dr. Munaz Mulla, Dr. Mushir Mulla. An in Vitro Comparative Evaluation of Microleakage of Conventional Gic \& New Modified Glass Ionomer Cement Nanozirconia Silica Hydroxyapatite Restorative Material. Int J Dentistry Oral Sci. 2021;8(9):4230-4232. doi: doi: http://dx.doi.org/10.19070/2377-8075-21000862

Copyright: Dr. Vikas Bulkar 2021 . This is an open-access article distributed under the terms of the Creative Commons Attribution License, which permits unrestricted use, distribution and reproduction in any medium, provided the original author and source are credited. 
Endodontics. It comprised of 80 freshly extracted maxillary first or second premolars. Inclusion criteria were caries free teeth, teeth extracted those indicated in case of orthodontic treatment. Exclusion criteria were carious teeth, teeth with evidence of fracture or abraded teeth. The study protocol was approved from institutional ethical committee.

All teeth were cleaned with scaler and polished followed by disinfection with $0.2 \%$ thymol solution for 48 hours and preserved in distilled water. In all teeth, cavity preparation was performed in the size of $3 \mathrm{~mm}$ X $3 \mathrm{~mm}$ X $2 \mathrm{~mm}$ in both lingual and labial side. Teeth were divided into two groups of 40 each. In group I, 10\% polyacrylic acid conditioner was applied to cavity for 10 seconds followed by insertion of GIC materials in the cavity following standardized procedure under manufacturer instruction. Similarly, in group II, after application of $10 \%$ polyacrylic acid conditioner, GIC-nanoZrO2-SiO2-HA hybrid material was placed.

All teeth were subjected to thermocycling for 500 cycles at the temperature of $5^{\circ} \mathrm{C}-55^{\circ} \mathrm{C}$. The nail varnish was applied to external surface of all teeth except a $1 \mathrm{~mm}$ wide margin surrounding the restoration. Teeth were then immersed in $2 \%$ methylene blue for 24 hours at the temperature of $37^{\circ} \mathrm{C}$ and then rinsed under running water. All teeth were cut with the help of diamond band saw in the middle of the restoration parallel to the occlusal surface. Each sample was assessed under stereomicroscope for the detection of marginal leakage of dye starting from the surface margins to the base of cavity preparation.

The degree of marginal leakage scoring was as following-

0 indicates no evidence of dye penetration at tooth- restoration interface, 1 indicates dye penetration along the interface to $\leq 1 / 2$ depth of cavity, 2 indicates dye penetration to full depth of cavity and 3 indicates dye penetration to base of cavity and beyond. Both labial and lingual surfaces were checked for microleakage.

\section{Statistical Analysis}

Result thus obtained were analyzed using SPSS version 21.0. Results were expressed in mean $\pm \mathrm{SD}$. Independent t- test was used for the assessing microleakage. P value less than 0.05 was considered significant.

\section{Results}

Table I, shows that group I comprised of $30(50 \%)$ teeth in which
Conventional GIC was used. Group II comprised of 30 teeth in which GIC-nano $\mathrm{ZrO} 2-\mathrm{SiO} 2-\mathrm{HA}$ was used.

Table II, Graph I shows that the mean microleakage in group I was $0.64 \pm 0.13$ and in group II was $0.89 \pm 0.12$. The mean difference in both groups found to be -0.43 . Independent $t-$ test showed significant difference between both groups $(\mathrm{P}<0.01)$.

\section{Discussion}

Microleakage is the biggest drawback with any restorative material. It is defined as ingress of fluid into the space between restoration ad tooth structures. Any restorative material should be capable of preventing micro- leakage. Thus a good restorative- tooth structure is of paramount importance in this regard. Post- operative sensitivity, penetration of bacteria, secondary caries formation, pulpal inflammation and marginal discoloration are complications among poor restorative material [5].

Hussin et al. [6] in their study suggested that microleakage of GIC leads post-operative sensitivity, secondary caries and poor marginal adaptation and ultimately failure of the restoration. In this study we evaluated micro- leakage of conventional GIC and modified glass ionomer cement-nanozirconia-silica-hydroxyapatite hybrid material. We included 80 freshly extracted maxillary molars which were divided into 2 groups. In group I, conventional GIC and in group II, modified GIC-nanoZrO2-SiO2-HA hybrid material was placed. We assessed microleakage with two restorative materials with the help of dye penetration test.

We observed that there was more microleakage in group II (modified GIC-nanoZrO2-SiO2-HA hybrid material) as compared to group I (conventional GIC fuji IX). The result of our study is in agreement with the results of Hussin HM. They divided freshly extracted mandibular premolars into 2 groups of 40 each. Microleakage was assessed in both groups. Group B in which modified GIC-nanoZrO2-SiO2-HA hybrid material was used possessed higher mean microleakage value as compared to conventional GIC IX.

Chemical trace method, dye penetration and scanning electron microscopy are various methods used for assessing microleakage. In present study we used dye penetration method [7]. Abdelaziz et al., [8] also utilized same dye penetration in their study. They evaluated microleakage in contemporary esthetic restorations following cyclic wet-dry storage. Class V cavities were prepared on

Table I. Distribution of teeth.

\begin{tabular}{|c|c|c|c|}
\hline \multicolumn{2}{|c|}{ Group I (Conventional GIC) } & \multicolumn{2}{c|}{ Group II (GIC-nano ZrO2-SiO2-HA) } \\
\hline No. & Percentage & No. & Percentage \\
\hline 40 & 50 & 40 & 50 \\
\hline
\end{tabular}

Table II. Comparison of microleakage between conventional GIC and GIC-nano ZrO2-SiO2-HA).

\begin{tabular}{|c|c|c|c|c|c|c|c|}
\hline \multirow{2}{*}{$\begin{array}{c}\text { Param- } \\
\text { eter }\end{array}$} & \multicolumn{2}{|c|}{ Group I } & \multicolumn{2}{c|}{ Group II } & \multirow{2}{*}{$\begin{array}{c}\text { Mean difference } \\
\mathbf{( 9 5 \%} \mathbf{~ C l )}\end{array}$} & t- statistics & P value \\
\cline { 2 - 5 } & Mean & SD & Mean & SD & -0.43 & -4.68 & 0.001 \\
\hline Grade & 0.64 & 0.13 & 0.89 & 0.12 & -0.43 & \\
\hline
\end{tabular}

Test used: Independent t- test, $\mathrm{P}<0.01$. 
Graph I. Comparison of microleakage between conventional GIC and GIC-nano ZrO2-SiO2-HA).

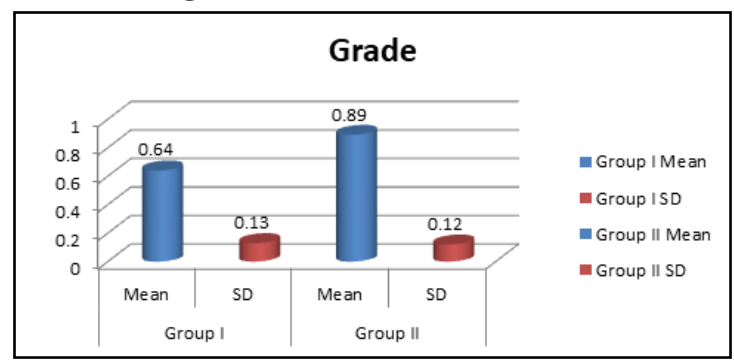

Test used: Independent t- test, $\mathbf{P}<0.01$.

both labial and lingual surfaces of freshly extracted 100 premolars which were divided into 10 groups. Various restorative materials were used and dye penetration method was employed. There was almost equal amount of microleakage in with all materials.

Mazaheri et al., [9] in their study included 50 deciduous canines in which class $\mathrm{V}$ cavities were prepared on buccal surfaces of all teeth. In group A teeth no conditioner was used, in group B 20\% acrylic acid, in group C 35\% phosphoric acid, in group D 12\% citric acid and in group E 17\% EDTA was used. Author found no significant difference of microleakage in any of restorative materials in incisal and gingival margins.

To enhance the life of any restorative material, there should be adequate seal at the margins. There is greater ionic bonding between the tooth and cement due to presence of higher mineral content in enamel [10].

Conventional GIC exhibits the advantage of a similar linear CTE as the tooth structure. There is production of stress because of difference of volumetric change between tooth and the restoration [11]. This stress may be exaggerated during the thermocycling test which ultimately affects the marginal seal. It has been observed that polymerization shrinkage results in failure of adhesion if there is poor bond strength between the tooth and restorative material [12].

Sharafeddin et al., [13] in their study assessed the microleakage of conventional and resin-modified Glass-ionomer cement in class $\mathrm{V}$ restorations by adding micro-hydroxyapatite and nanohydroxyapatite in GIC. This study comprised of 30 extracted mandibular molar. The cavities were restored in six experimental groups. Group 1 was restored with conventional glass-ionomer cement (CGIC); group 2 with CGIC micro-HAP, group 3 with CGIC nano-HAP, group 4 with RMGI, group 5 with RMGI micro-HAP and group 6 with RMGI nano-HAP.

It was found that in groups 1, 3 and 4, the microleakage of occlusal margin were significantly lower than that of gingival margin. In groups 5 and 6 at both occlusal and gingival margins, the gingival microleakage was significantly lower than occlusal margin. Rehaman et al., [14] suggested that higher content of nanosilica produced a denser and stronger GIC. Thus, the application of nanohydroxyapatite-silica-GIC with improved properties is envisioned to be of great clinical importance, especially in stress bearing areas.

The limitation of the present study is that small sample size was selected. Moreover only 2 types of GIC were compared. The inclusion of various restorative materials could have shown differ- ent results.

\section{Conclusion}

Though there are modifications in glass ionomer cements, the modified GIC-nanoZrO2-SiO2-HA hybrid material exhibited higher microleakage as compared to conventional GIC.

\section{References}

[1]. Geissberger M. Esthetic dentistry in clinical practice. John Wiley \& Sons; 2013 Jul 8.

[2]. Delmé KI, Deman PJ, De Bruyne MA, Nammour S, De Moor RJ. Microleakage of glass ionomer formulations after erbium:yttrium-aluminium-garnet laser preparation. Lasers Med Sci. 2010 Mar;25(2):171-80. Pubmed PMID: 18716828.

[3]. Gupta SK, Gupta J, Saraswathi V, Ballal V, Acharya SR. Comparative evaluation of microleakage in Class $V$ cavities using various glass ionomer cements: An in vitro study. Journal of Interdisciplinary Dentistry. 2012 Sep $1 ; 2(3): 164$.

[4]. Yavuz I, Aydın H. New direction for measurement of microleakage in cariology research. J Int Dent Med Res. 2010 Mar 1;3(1):19-24.

[5]. Craig RG. Restorative Dental Materials. 9th ed. St. Louis: Mosby Publishing Co.; 1993; 42-3.

[6]. Hussin HM, Bakar WZ, Ghazali NA, Sajiad A. Microleakage assessment of a new modified glass ionomer cement-nanozirconia-silica-hydroxyapatite restorative material. Journal of International Oral Health. 2018 May $1 ; 10(3): 138$

[7]. Majety KK, Pujar M. In vitro evaluation of microleakage of class II packable composite resin restorations using flowable composite and resin modified glass ionomers as intermediate layers. J Conserv Dent. 2011 Oct;14(4):4147. Pubmed PMID: 22144815.

[8]. Abdelaziz KM, Abogazalah NN, El-malky W. Microleakage in contemporary esthetic restorations following cyclic wet-dry storage. The Saudi Journal for Dental Research. 2016 Jul 1;7(2):81-90.

[9]. Mazaheri R, Pishevar L, Shichani AV, Geravandi S. Effect of different cavity conditioners on microleakage of glass ionomer cement with a high viscosity in primary teeth. Dent Res J (Isfahan). 2015 Jul-Aug;12(4):337-41. Pubmed PMID: 26288623

[10]. Singla T, Pandit IK, Srivastava N, Gugnani N, Gupta M. An evaluation of microleakage of various glass ionomer based restorative materials in deciduous and permanent teeth: An in vitro study. Saudi Dent J. 2012 Jan;24(1):35-42. Pubmed PMID: 23960526.

[11]. Nakamura K. Mechanical and microstructural properties of monolithic zirconia. 2015 Mar 25

[12]. Moshaverinia A, Roohpour N, Chee WW, Schricker SR. A review of powder modifications in conventional glass-ionomer dental cements. Journal of materials chemistry. 2011;21(5):1319-28.

[13]. Sharafeddin F, Feizi N. Evaluation of the effect of adding micro-hydroxyapatite and nano-hydroxyapatite on the microleakage of conventional and resin-modified Glass-ionomer Cl V restorations. J Clin Exp Dent. 2017 Feb 1;9(2):e242-e248. Pubmed PMID: 28210443.

[14]. Ab Rahman I, Ghazali NA, Bakar WZ, Masudi SA. Modification of glass ionomer cement by incorporating nanozirconia-hydroxyapatite-silica nanopowder composite by the one-pot technique for hardness and aesthetics improvement. Ceramics international. 2017 Nov 1;43(16):13247-53. 